\title{
Addressing the sexual and reproductive health needs of young people: Perspectives and experiences of stakeholders from the health and non-health sectors
}

\author{
K.G. Santhya \\ Population Council \\ Shireen J. Jejeebhoy \\ Population Council \\ Saswata Ghosh \\ Nicole Haberland \\ Population Council
}

Follow this and additional works at: https://knowledgecommons.popcouncil.org/departments_sbsr-pgy

Part of the Demography, Population, and Ecology Commons, Family, Life Course, and Society Commons, International Public Health Commons, Maternal and Child Health Commons, and the Medicine and Health Commons

How does access to this work benefit you? Let us know!

\section{Recommended Citation}

Santhya, K.G., Shireen J. Jejeebhoy, Saswata Ghosh, and Nicole Haberland. 2007. "Addressing the sexual and reproductive health needs of young people: Perspectives and experiences of stakeholders from the health and non-health sectors," Research update. New Delhi: Population Council. 


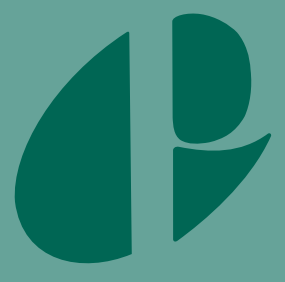

\section{ADDRESSING THE SEXUAL AND REPRODUCTIVE HEALTH NEEDS OF YOUNG PEOPLE: Perspectives and experiences of stakeholders from the health and non-health sectors}

\section{Background}

In India, several recent policies, including the National Population Policy 2000 and the National Youth Policy 2003, have underscored the right of adolescents and youth to sexual and reproductive health (SRH) counselling and services. Similarly, the recently launched Reproductive and Child Health (RCH) Programme II proposes to deliver a wide range of services to adolescents and youth, including contraceptive supplies, pregnancyrelated care, management of symptoms of infection, as well as counselling for a range of sexual and reproductive matters during routine sub-centre visits and weekly teen clinics at primary or community health centres. $\mathrm{RCH}$ programme strategies also suggest efforts to orient medical officers, auxiliary nurse-midwives (ANMs) and lady health visitors in the provision of various sexual and reproductive health services to young people. A number of other government departments and NGOs also address the needs of young people.

Despite these policies and programmes, little information is available on the extent to which policy recommendations and programme strategies have been implemented, and the extent to which services actually serve the disparate needs of married and unmarried young women and men. Similarly, there is limited evidence about the extent to which health care providers at different levels of service delivery and stakeholders from other sectors are involved in providing sexual and reproductive health and $\mathrm{HIV} / \mathrm{AIDS}$ related information and services to young people; or their perceptions about the vulnerability of young people in general, or of different sub-groups of young people, for example, married young people, in particular. In an effort to fill this gap, the Population Council undertook a small-scale study among stakeholders from the health and non-health sectors to assess their interaction with young people, their perceptions about the vulnerability of young people and the factors that facilitate or hinder their capacity to provide SRH information and services to this group.

\section{Description of the project}

Sites: The study was conducted in rural settings in Guntur district of Andhra Pradesh, characterised by low median age at marriage and first birth, and high levels of STI/HIV, and in Dhar and Guna districts of Madhya Pradesh, characterised by low median age at marriage and first birth, and low levels of STI/HIV. These two contrasting settings were selected to explore the extent to which the perceptions of different stakeholders about married young people's SRH vulnerability, including to STI/HIV, their experiences in delivering services to married young people and above all, married young people's ability to adopt protective behaviours, differ in settings at different stages of the HIV epidemic even while such structural factors as age at marriage are similar.

Study design: Study participants included stakeholders from both the health and non-health sectors who provide SRH information or services to young people, or interact with young people. Respondents from the health sector included all categories of providers at the sub-centre, primary health centre and community health centre level as well as village health volunteers, if available. Participants from other sectors included representatives from the Integrated Child Development Services, teachers from high schools, and representatives of women's and youth groups, NGOs and panchayats. Data collection was carried out during June-August 2006. A brief structured questionnaire was administered to all respondents. A total of 599 stakeholders were contacted; 93 percent were 
successfully interviewed. Also conducted were eight in-depth interviews with medical officers and 12 focus group discussions with ANMs.

\section{Findings}

Findings confirm that stakeholders from the health and non-health sectors in both sites do indeed interact with young people. Most stakeholders appeared however to be more likely to interact with young women rather than young men, the married rather than the unmarried, and those out of school rather than those in school. This is not surprising given the practice of early marriage in both sites and the predominance of female stakeholders in our sample.

The vast majority of stakeholders provided SRH information. However, thematic emphases varied: HIV/STI-related information featured prominently in Guntur, while nutrition and pregnancy care were stressed in Dhar and Guna.

Service provision by health sector stakeholders to young people was far from universal. Over threequarters reported the provision of family planning and antenatal counselling, contraceptive supplies, and antenatal and post-partum care. However, screening of pregnant women for syphilis and HIV, and delivery services were provided by fewer than half, and abortion services by far fewer. In the area of STIs and HIV/AIDS, counselling was far more likely to be provided in Guntur than in Dhar and Guna, but diagnosis and treatment services were provided by one-quarter or fewer health sector providers in both settings. Contrary to general perceptions, a significant minority of health sector stakeholders in both sites reported providing contraceptives to the unmarried.

While a substantial proportion of stakeholders in both sites recognise married young people's vulnerability to STI/HIV, there is a lack of recognition of their special health service needs. Large proportions of stakeholders reported that married young women are no more likely to be in need of health services than married adult women or unmarried young women; similar views were reported in the case of married young men.

Findings underscore a number of factors that might hinder the ability of stakeholders to provide SRH information and services to young people, and specifically, to the married. A major obstacle was stakeholders' own discomfort in providing sexuality-related information and services to different groups of youth: while most stakeholders were comfortable discussing these topics with married young women, sizeable proportions reported discomfort in addressing young men, and in Dhar and Guna, even unmarried young women. Another significant obstacle was the lack of training on providing information on SRH to young people, and, among health care providers, on related service delivery issues. The dearth of relevant information materials was also an obstacle. Wide variation was observed in both training and the availability of information materials by setting: stakeholders in Guntur were, in general, far more likely to have received training, particularly on such issues as HIV/AIDS and to report the availability of information materials than were those from Dhar and Guna. Aside from HIV, in both settings, training was considerably more likely to be reported and information materials available on such topics as contraception and care during pregnancy rather than on safe abortion. Findings also highlight a tendency among providers to accede to traditional social norms and thus, while providers are certainly aware of the isolation of married young girls, and the pressures that newly-married couples face to bear children, they typically do not make efforts to tailor communication messages or services to enable married youth to overcome these constraints.

\section{Implications for programmes}

Findings have reiterated that stakeholders in the health and non-health sectors are a valuable resource through whom to deliver information and services to young people. Efforts are needed to tap these multifaceted stakeholders and equip them to address the multiple and varied needs of youth. Programmes must sensitise stakeholders about the unique needs of different categories of youth, enable them to overcome inhibitions about communicating with youth on sensitive sexual and reproductive matters, and apprise them of gender and social biases that increase young women's vulnerability. Their roles as providers of information and services must be recognised and strengthened so that they may serve young people's needs holistically and reach even the most isolated.
For further information please contact:

Population Council

Zone 5A, Ground Floor

India Habitat Centre, Lodi Road

New Delhi - 110 003, India

Tel: 91-11-2464 2901/02

Fax: 91-11-2464 2903

Email: info-india@popcouncil.org

\section{www.popcouncil.org}

Contributors

KG Santhya

Shireen Jejeebhoy

Saswata Ghosh

Nicole Haberland

Donor

Department for International

Development, UK 